\title{
Evaluation of MYC Gene Amplification in Prostate Cancer Using a Dual Color Chromogenic In Situ Hybridization (Dual CISH) Assay
}

\author{
Lerda Daniel $^{1}$, Cabrera Marta ${ }^{2}$, Flores Jorge ${ }^{2}$, Gutierrez Luis ${ }^{3}$, Chierichetti Armando ${ }^{3}$, \\ Paladini Mario $^{3}$, Revol Martin ${ }^{3}$, Garcia Önto Hernan $^{3}$
}

${ }^{1}$ Genetic Laboratory, Medicine School, Cordoba Catholic University, Córdoba, Argentina

${ }^{2}$ Pathology Laboratory of Cordoba Aeronautico Hospital, Córdoba, Argentina

${ }^{3}$ Urology Department of Cordoba Aeronautico Hospital, Córdoba, Argentina

\section{Received: November 19, 2012 \\ Accepted: January 17, 2013 \\ Published Online: January 28, 2013 \\ DOI: $10.5455 /$ jihp. 20130117075557 \\ Corresponding Author: \\ Daniel Lerda, \\ Genetic Laboratory, Medicine School, Cordoba Catholic University, Córdoba, Argentina \\ dlerda@coyspu.com.ar}

Keywords: MYC, prostate cancer, chromogenic in situ hybridization, CISH

\begin{abstract}
Objective: The overall purpose of the study was to demonstrate applicability of the DAKO dual-color chromogenic in situ hybridization (CISH) assay (DAKO Denmark, Glostrup) with respect to fluorescence in situ hybridization (FISH) probes MYC-C.

Methods: MYC gene amplification by FISH and DAKO dual-color CISH

Results: The study showed that the dual-color CISH assay can convert Texas red and fluorescein isothiocyanate (FITC) signals into chromogenic signals. The dual-color CISH assay was performed on 40 cases of prostate cancer. Amplification was identified in 12 of $40(30 \%)$ tumors. No amplification was seen in 28 of $40(70 \%)$ tumors. FISH data were available in total of 40 tumors. All tumors showed concordant results between dual-color CISH and FISH for classifying a tumor as $M Y C$ amplified or not amplified. Conclusions: We conclude that dual-color DAKO CISH assay is an accurate method for determining $M Y C$ gene amplification with added advantages that make it a more practically useful method.
\end{abstract}

\section{INTRODUCTION}

Prostate cancer $(\mathrm{PCa})$ is a common malignancy in men in Western countries, has the characteristics of a heterogeneous damage with multiple risk factors [1]. The increase in the incidence of PCa in the last twenty years has assumed almost epidemic proportions because this neoplasm is the most frequently diagnosed solid tumor and that in our country is the second leading cause of death oncology [2]. There is consistent evidence that PCa deaths have decreased over the last decade, most likely associated with the extensive use of prostate specific antigen (PSA) in the early diagnosis of the disease [3].The $8 \mathrm{q} 24.21$ region, where $\mathrm{MYC}$ is located, is contained within a region that is commonly amplified in prostate cancer, especially in advanced and recurrent disease [4]. By chromosome microdissection, 8 q24 amplification was first identified in 2 prostate cancer cases [4]. To verify this, fluorescence in situ hybridization (FISH) was carried out on 44 prostatectomy samples, and the amplification was present in only $9 \%$ of the total cases studied but $75 \%$ of advanced cases. Accordingly, in the study of patients with recurrent disease, comparative genomic hybridization and FISH analysis showed 8q24 amplification in 8 of 9 cases [4].

Because the amplification of the $8 \mathrm{q} 24$ region is predominantly observed in late-stage/aggressive tumors, it has been widely held that MYC is involved in disease progression [4]. Interestingly, the amplification of MYC is generally on the order of a 
few fold; high-level amplifications, such as those seen with MYC-N in a subset of neuroblastomas, are virtually never seen in prostate cancer.

Fluorescence in situ hybridization (FISH) has achieved widespread use for a range of gene copy number detection probes and translocation probes. It is considered a very accurate and sensitive method, e.g., the College of American Pathologists has published that FISH is to be regarded as "gold standard" for HER2 testing [5]. However, the FISH method is perceived as having some limitations. The evaluation of tumor morphologic features through FISH may be difficult, and the method requires a fluorescence microscope, which is costly and not readily available in all pathology laboratories.

Furthermore, the fluorescence signals fade relatively quickly, which makes archiving of the slides difficult. These limitations can be overcome by chromogenic in situ hybridization (CISH), which converts the fluorescence signals into chromogenic precipitates, and can visualize FISH-labeled probes along with the morphologic features using a brightfield microscope [6].

Hoff et.al [6] developed a dual-color CISH assay in which the green fluorescein isothiocyanate (FITC) FISH signals are converted into red chromogenic precipitates $[7,8]$.

The purpose of this study was demonstrate the general use of the DAKO dual-color CISH assay (DAKO Denmark, Glostrup) by applying it to gene copy detection probe as $M Y C-C$.

\section{MATERIAL AND METHODS}

\section{Case Selection}

Archival formalin-fixed paraffin-embedded tissues from 40 prostate cancers were randomly selected. An H\&E stained section was evaluated for the presence of prostate cancer and used for assessment of MYC gene amplification by FISH and DAKO dual-color CISH.

\section{Fluorescence In Situ Hybridization}

The FISH analyzes for $M Y C-C$ were performed using FISH probes for C-MYC, respectively (DAKO) in combination with the Histology FISH Accessory kit (DAKO) (Code K5599). The FISH analyses for $M Y C$ - $C$ were performed using the FISH (DAKO) assays. All staining were performed according to the respective package insert and subsequently evaluated using a fluorescence microscope. The slides that were analyzed using the dual-color CISH kit followed the same protocols but were not mounted.

\section{Chromogenic In Situ Hybridization}

The dual-color CISH (Code SK 108) assay contains reagents required to complete a 2-step immunohistochemical staining procedure to detect DAKO Texas red- and FITC-labeled FISH probes. First, the aforementioned FISH procedures were followed, except the last dehydration and mounting step was omitted and the tissue specimens for CISH analysis were immersed in the CISH Wash Buffer (DAKO). The next step in the CISH procedure is to block the tissue specimens for endogen peroxidase with a ready-to-use Peroxidase Blocker (DAKO). Peroxidase blocking is followed by incubation with a ready- to- use CISH Antibody Mix (DAKO), which comprises a mixture of anti-FITC conjugated with horseradish peroxidase and anti-Texas red conjugated with alkaline phosphatase. Tissue specimens were then incubated with a red chromogen followed by incubation with a blue chromogen [6]. Finally, the specimens were counterstained with hematoxylin (DAKO Hematoxylin - Code S3301) and coverslipped (Tissue-Mount, Aquatex de Merck), and the results were evaluated using a bright-field microscope.

\section{Interpretation of Staining}

Samples were scored according to the guidelines provided with the FISH probe used with the DAKO DuoCISH kit. However, the CISH signals are slightly larger than the corresponding FISH signals. For all tumor specimens in this study signals from 20 nuclei were counted.

\section{RESULTS}

In the forty patients studied, the average age was 63 years, with a median of 63.5 years, the youngest was 51 years and the largest 73. Twelve patients showed amplification of C-MYC gene, showing a prevalence of $30 \%$ of the sample.

The dual-color CISH assay was tested with MYC-C probe. This was qualitative, evaluating the general appearance of $\mathrm{CISH}$ staining with respect to tissue morphologic features and the balance between red and blue signal size, sharpness, and intensity. For the probe, the general appearance seemed almost identical between the 2 methods (Figure 1).

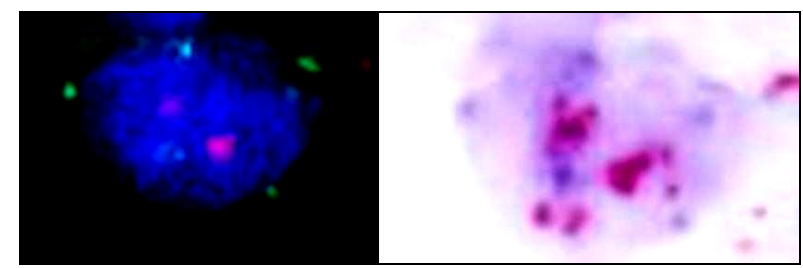

Figure 1. Dot-to-dot conversion of FISHsignals to $\mathrm{CISH}$ signals. 


\section{DISCUSSION}

The present study showed that the dual-color CISH assay can convert Texas red and FITC FISH signals into chromogenic signals in context with preserved morphologic features. A number of previously published studies with HER2 probes have likewise shown high concordance between FISH and CISH assays, in the range of $91 \%$ to $100 \%$, which seems to confirm the reliability of CISH [9-12].

The $M Y C-C$ sensitizes cells to a wide range of proapoptotic stimuli. During apoptosis, $M Y C$ - $C$ induces the release of cytochrome $\mathrm{c}$ from mitochondria into the cytosol, possibly through the activation of proapoptotic molecule BAX. Similarly, other authors sought this type of alterations in prostate cancer. [1315]. Pflueger et al [16], where they have identified NDRG1-ERG fusion in prostate tumors in $44 \%$ of patients $(\mathrm{n}=100)$ who received radical prostatectomy, also considering patients with advanced disease. This identification of NDRG1-ERG fusion results in the formation of chimeric proteins in prostate cancer and has potential clinical and biological implications. The NDRG1 is involved in cell differentiation, suppressed by the oncogenes N-MYC and C-MYC and therefore often deregulated in cancer cells. It is expected that the testing of dual-color CISH in a relatively short time, is an accepted method in the routine evaluation of diagnosis of the situation in the different types of cancer. Using a light microscope instead of a fluorescence microscope and the ability to easily observe the morphological characteristics of the fund will be seen as advantages over current FISH assays. Based on data from different studies $[6,17,18]$, our experience using the technique of CISH [19-23] and the results of this study, the dual-color DAKO CISH assay appears to be sensitive and specific, and because of his familiarity with immunohistochemical analysis, which may have the potential to be the most used in pathology laboratories in the future.

\section{ACKNOWLEDGMENTS}

This work was carried out with a grant from a Scholarship in Fiorini Foundation of

Buenos Aires, Argentina.

\section{CONFLICTS OF INTEREST}

The authors declare that they have no conflict of interest.

\section{REFERENCES}

1. Wein, AJ, Novick AC, Kavoussi LR, Partin AW, Peters CA. In: Campbell-Walsh (ed) Urology, $9^{\text {th }}$ edition Saunders/Elsevier, Philadelphia, PA, 2007.

2. Atlas de mortalidad por Cáncer Argentino 1997-2001. Matos EL, Loria DI, Singanini N. Instituto de Oncología Angel H Roffo, Buenos Aires, 2003.

3. Sthephenson RA. Prostate cancer trends in the era of prostate- especific antigen. And update the incidence mortality and clinical factors from SEER data base. Urol Clin North Am 2002; 29: 173181.

4. Koh CM, Bieberich CJ, Dang CV, Nelson N, Yegnasubramanian S, De Marzo A. MYC and Prostate Cancer. Genes \& Cancer 2010, 1:617-628.

5. Wolff AC, Hammond EH, Schwartz JN, Hagerty KL, Allred DC, Cote RJ, Dowsett M, Fitzgibbons PL, Hanna WM, Langer A, McShane LM, Paik S, Pegram MD, Perez EA, Press MF, Rhodes A, Sturgeon C, Taube SE, Tubbs R, Vance GH, Vijver M van de, Wheeler TM. American Society of Clinical Oncology/College of American Pathologists guideline recommendations for human epidermal growth factor receptor 2 testing in breast cancer. J Clin Oncol 2007; 25:118-145.

6. Hoff K, Jørgensen J, Müller S, Røngaard E, Rasmussen O and Schønau A. Visualization of FISH Probes by DualColor Chromogenic In Situ Hybridization. Am J Clin Pathol 2010; 133:205-211.

7. Tanner M, Gancberg D, DiLeo A, Larsimont D, Rouas G, Piccart M, Isola J. Chromogenic in situ hybridization to detect HER- 2/neu oncogene amplification in archival breast cancer samples. Am J Pathol 2000; 157:1467-1472.

8. Knuutila S, Bjorkqvist AM, Autio K, Tarkkanen M, Wolf M, Monni O, Szymanska J, Larramendy ML, Tapper J, Pere H, El-Rifai W, Hemmer S, Wasenius VM, Vidgren $\mathrm{V}$, Zhu Y. DNA copy number amplifications in human neoplasms: review of comparative genomic hybridization studies. Am J Pathol 1998; 152:1107-1123.

9. Hauser-Kronberger C, Dandachi N. Comparison of chromogenic in situ hybridization with orther methodologies for HER 2 status assessment in breast cancer. J Mol Histol 2004; 35:647-653.

10. Gong Y, Gilerease M, Sneige N. Reliability of chromogenic in situ hybridization for detecting HER -2 gene status in breast cancer: comparison with fluorescence in situ hybridization and assessment of interobserver reproducibility. Mod Pathol 2005; 18:10151021.

11. Vocaturo A, Novelli F, Benevolo M, Piperno G, Marandino F, Cianciulli AM, Merola, R, Donnorso RP, R Sperduti I, Buglioni S, Mottolese M. Chromogenic in situ hybridization to detect HER2/neu gene amplification in histological and ThinPrep-processed breast cancer fineneedle aspirates: a sensitive and practical method in the trastuzumab era. Oncologist 2006; 11:878-886.

12. Dietel M, Ellis IO, Höfler H, Kreipe H, Moch H, Dankof A, Kölble K, Kristiansen G. Comparison of automated 
silver enhanced in situ hybridization (SISH) and fluorescence ISH (FISH) for the validation of HER2 gene status in breast carcinoma according to the guidelines of the American Society of Clinical Oncology and the College of American Pathologists. Virchows Arch. 2007; 451:19-25.

13. Nupponen NN, Visakopi T. Molecular cytogenetics of prostate cancer. Microsc Res Tech 2000; 51(5):456-463.

14. Verma RS, Manikal M, Conte RA, Godec CJ. Chromosomal basis of adenocarcinoma of the prostate. Cancer Invest 1999;17(6):441-447.

15. Wolter H, Gottfried HW, Mattfeldt T. Genetic changes in stage pT2N0 prostate cancer studied by comparative genomic hybridization. BJU Int. 2002; 89(3):310-316.

16. Pflueger D, Rickman DS, Sboner A, Perner S, LaFargue C, Svensson M, Moss B, Kitabayashi N, Pan Y, de la Taille A, Kuefer R, Tewari A, Demichelis F, Chee M, Gerstein M, and Rubin M. N- myc downstream regulated gene 1 (NDRG1) is fused to ERG in prostate cancer. Neoplasia 2009; 11(8): 804-811.

17. Pedersen M and Rasmussen, B. The correlation Between Dual-color Chromogenic In Situ Hybridization and Fluorescence In Situ Hybridization in Assessing HER 2 Gene Amplification in Breast cancer. Diagnostic Mol Pathol 2009; 18(2):96-102.

18. Kato N, Itoh H, Serizawa A, Hatanaka Y, Umemura S,
Yoshiyuki Osamura R. Evaluation of HER2 gene amplification in invasive breast cancer usinf a dual-color chromogenic in situ hybridization (dual CISH). Pathol Int 2010; 60(7): 510-515.

19. Lerda D, Sambuelli R. Bella S, Guidi, A. Armando, L Gomez S. La Hibridización Cromogénica in situ (CISH) en el diagnóstico oncológico Documento de trabajo. Serie Medicina, Universidad Católica de Córdoba, EDUCC, pp $1-29,2008$.

20. Bella S, Gudi A, Lerda D, Sambuelli R Armando L. HER2 amplification through CISH-chromogenic hybridization in situ-on breast cancer Her $22+$ by immunohistochemistry (ICH). J Clin Oncol 2008; 26 (Suppl):22147.

21. Bella S, Lerda D, Guidi A, Armando L. Genetic changes during colorectal cancer development. J Clin Oncol 2009; (Suppl): 11110.

22. Bella S, Theaux R, Lerda D. Evaluation of $1 p$ and $19 q$ deletion by chromogenic in situ hybridization (CISH) in paraffin embedded central nervous system oligodendroglial tumors (CONSOT). J Clin Oncol 2010; (suppl, abstr e 12557): 28.

23. Suarez J, Theaux R, Lerda D, Guidi A, Armando L. Nuestra experiencia en el manejo de los gliomas cerebrales de bajo grado, astrocitomas y oligodendrogliomas, en la infancia. Rev Argent Neuroc 2011; 25:71-77.

This is an open access article licensed under the terms of the Creative Commons Attribution Non-Commercial License which permits unrestricted, non-commercial use, distribution and reproduction in any medium, provided the work is properly cited. 